|Araştırma Makalesi / Research Article |

\title{
Ortaokul Öğrencilerinin Artırımış Gerçeklik Uygulamalarının Eğitimde Kullanımına Yönelik Tutumları: Siirt ili Örneği
}

\section{Attitudes of Secondary School Students towards the Use of Augmented Reality Applications in Education: Sample of Siirt Province}

\section{Mehmet RAMAZANOĞLU ${ }^{1}$, Mehmet Şahin SOLAK ${ }^{2}$}

\author{
Anahtar Kelimeler \\ artırılmış gerçeklik \\ ortaokul öğrencileri \\ qr kod \\ unity
}

\section{Keywords \\ augmented reality secondary students qr code \\ unity}

Başvuru Tarihi/Received 18.11.2019

Kabul Tarihi /Accepted 02.05.2020
Öz

Bu çalışmanın amacı, ortaokul öğrencilerinin artırılmış gerçeklik uygulamalarının eğitimde kullanımına yönelik tutumlarını incelenmesidir. Çalışmada karma model yöntemlerinden eşzamanlı üçgenleme tasarım kullanılmıştır. Çalışma katılımcılarını, 2018-2019 eğitim-öğretim yılında Siirt ilinde bulunan bir ortaokulun 6. sınıfında öğrenim gören 44 öğrenci oluşturmaktadır. Çalışma gurubunun seçiminde uygun örnekleme yöntemi kullanılmıştır. Nicel bölümde çalışmaya katılanların artırılmış gerçeklik uygulamalarına karşı tutumlarının belirlenmesi için "Artııımış Gerçeklik Uygulamaları Tutum Ölçeği”" kullanılmıştır. Nitel bölümde ise yarı yapılandırılmış görüşme formu kullanılmıştır. Verilerin analizi için SPSS 21 programı ve betimsel analiz yöntemi prosedürleri uygulanmıştır. Elde edilen verilerin sonucunda artırımış gerçeklik uygulamalarının eğitimde kullanımına yönelik ortaokul öğrencilerinin tutum düzeylerini olumlu yönde etkilediğini ve görüşlerinin olumlu olduğu bulunmuştur. Çalışmada öğrencilerinin artırılmış gerçeklik uygulamalarının eğitimde kullanımına yönelik kullanma kaygılarının azaldığını ve kullanma isteklerinin arttığı sonucuna varılmıştır. Öğrencilerin artırılmış gerçeklik uygulamalarının eğitimde kullanımına yönelik kullanma memnuniyetlerinin arttığı, ancak istatiksel olarak anlama bulunmamıştır. Çalışmada hem erkek öğrencilerin hem de kadın öğrencilerin artırılmış gerçeklik uygulamalarının eğitimde kullanıma ilişkin tutum düzeylerinin aynı seviyede olduğu görülmüştür.

\section{Abstract}

The aim of this study is to analyse the attitudes of secondary school students towards the use of augmented reality applications in education. Concurrent triangulation research design which is one of the mixed model methods has been used in the study. The participants of the study consist of 44 students who are receiving education in the 6th grade of a secondary school in Siirt province during 2018-2019 academic year. Convenience sampling method has been used in the selection of the study group. In the quantitative part, "Augmented Reality Applications Attitude Scale" has been used in order to determine the attitudes of the participants related to the augmented reality applications. In the qualitative part, semi-structured interview form has been used. SPSS 21 program and descriptive analysis method procedures have been applied for data analysis. As a result of the data obtained from the study, it was found that augmented reality applications positively affect the attitude levels of secondary school students towards their use in education and they had positive opinions. In this study, it was observed that anxiety of the students regarding the use of augmented reality applications in education decreased and their willingness to use these applications increased. Students' satisfaction with the use of augmented reality applications in education increased; however, it was not statistically significant. In the study, it was seen that both male and female students had the same level of attitudes towards the use of augmented reality applications in education.

\footnotetext{
${ }^{1}$ Sorumlu Yazar, Siirt Üniversitesi, Eğitim Fakültesi, Bilgisayar ve Öğretim Teknolojileri Eğitimi Bölümü, Siirt, TÜRKiYE; http://orcid.org/0000-0001-6860-0895 ${ }^{2}$ Siirt Üniversitesi, Eğitim Fakültesi, Bilgisayar ve Öğretim Teknolojileri Eğitimi Bölümü, Siirt, TÜRKiYE; http://orcid.org/0000-0003-2528-7960
} 



\section{Extended Abstract}

\section{Introduction}

The reflections of the new technologies that have been used in military, space and medical fields in recent years can also be seen in the field of education. The most attention grabbing features of using these technologies in the educational environments are that they facilitate learning of the individuals, increase their effectiveness in the learning environments and provide rich learning experiences. On the other hand, changes in learning environments occur within the framework of the needs and demands of societies (Odabaşı, 2010). In particular, virtual environments have been created for the use of individuals by making the available software and hardware technologies that are in use three dimensional as output.

Augmented reality applications (AR) which is one of these environments used mostly in areas other than education, offers individuals experience of the real world and the virtual world in the same space and time frame (Azuma, 1997). As the costs of augmented reality technologies are reduced and these technologies become accessible and usable, their potential in teaching environments has increased (Somyürek, 2014). It has been stated that the increasing use of augmented reality technologies in educational environments is due to a number of characteristics of young individuals. It is aimed to investigate the existence and effective usability of augmented reality technologies in educational environments with this study. The attitudes of secondary school students in the study group towards augmented reality and their views on these technologies were of interest. Findings in the literature that show the use of AG technologies in the lessons increase the interest, curiosity and willingness of the students towards the lesson, they had positive attitudes regarding AG and AG applications increase their motivation and incentive towards the lesson makes the subject worth researching. From this point of view, the aim of this study is to investigate and analyse the attitudes of secondary school students towards the use of augmented reality applications in education.

\section{Method}

Concurrent triangulation research design which is one of the mixed model methods has been used in this research. Pre-test and post-test single group weak experimental design which is one of the quantitative research methods has been used in the study. In the research, descriptive analysis method has been used as the qualitative research method. The participants of the study consist of 44 students who are receiving education in the 6th grade of a secondary school in Siirt province during 2018-2019 academic year and who have participated in the study voluntarily. Convenience sampling method has been used in the selection of the study group.

In the application stage of the study, 3 dimensional (3D) and 2 dimensional (2D) animation and video materials were designed by the researcher regarding the subject of electronic century and nuclear energies in the 7th unit of the 6th grade Social Studies course curriculum. In this process, Unity 3D software was used for material preparation. The designed materials were presented to the students through creating QR codes. Students interacted with the designed materials by using Cardboard virtual glasses. Prepared materials were used by the teachers for a total of five weeks ( 20 hours) within the lessons. Smart phone were selected as the application tool among the mobile devices due to its ease of use and accessibility throughout the application conducted in the study.

In the quantitative section, the "Augmented Reality Applications Attitude Scale" which was developed by Küçük, Yılmaz, Baydaş and Göktaş (2014) and which consisted of "the use satisfaction", "the use anxiety" and "the use willingness" dimensions was used before and after the application in order to determine the attitudes of the experimental group participated in the study towards the augmented reality applications. In the qualitative section, semi-structured interview form was used. A question pool was created for this form and these questions were presented to 3 experts working in the fields of Turkish and Computer and Instructional Technology Education in order to ensure the content validity of the questions. In accordance with the suggestions and opinions of the experts, 2 questions were included in the semi-structured interview form. In the analysis of the quantitative data, SPSS 21 program was used to determine the attitudes of the experimental group towards the augmented reality applications. Descriptive analysis method was used in the analysis of qualitative data.

\section{Result and Discussion}

The aim of this study was to investigate the attitudes of secondary school students towards the use of augmented reality applications in education. Within this direction, it was determined that the use satisfaction of the secondary school students regarding the use of augmented reality applications in education was high, the use anxiety of the students were low and the students were undecided in terms of the use willingness. However, it was observed that the use of augmented reality applications in education affected their attitude levels towards the use of augmented reality applications in education. Accordingly, it was concluded that anxiety of the students related to using augmented reality applications in education decreased and their willingness to use these applications increased. Students' satisfaction with the use of augmented reality applications in education increased; however, it was not statistically significant. The possible reasons for this situation can be due to the fact that the use of augmented reality applications for educational purposes will provide effective participation in the lessons, increase permanent learning, increase attention, attract attention, make the lessons more fun, facilitate learning, increase the motivation, form a 
sense of reality, create difference, be more productive, provide active participation in the lessons, be beneficial to use in the lessons and help to reinforce subjects of the lessons. In the qualitative data, the students expressed similar opinions. Similarly, Di Serio, Ibanez and Kloos (2013) found that augmented reality practices affect students' attitudes and motivations towards learning. Küçük, Yılmaz and Göktaş (2014) in their study stated that the fifth grade secondary school students of seven schools in which they conducted their study were satisfied with the use of augmented reality applications, their use anxiety decreased and they wanted to use these applications in other courses as well. Ibáñez, Di Serio, Villarána and Kloosa (2014) concluded that augmented reality applications provided effective learning in their experimental study that they conducted with 64 high school students. Chiang, Yang and Hwang (2014) stated that mobile augmented reality applications increased the motivation of students in their experimental study that they conducted with fourth grade students in northern Taiwan. In the study conducted by İzi Onbaşlı (2018), it was concluded that augmented reality practices affect the attitudes and motivations of fourth grade students significantly. In addition, students expressed that augmented reality applications made the lessons more entertaining, increased their interest in the lessons, facilitated their learning and they wanted them to be used in other courses related to the use of augmented reality applications in classroom environment. Ramazanoğlu and Aker (2019) in their study related to the use of augmented reality applications in the learning environment, it was seen that students expressed a positive opinion about the use of augmented reality applications. Unlike the results of the studies stated above, Yıldırım (2016) in his study stated that the use of augmented reality applications did not affect the attitudes of the students, the augmented reality applications contributed to learning processes of the students, the lessons became more entertaining and their success in the lessons increased.

In the study, it was seen that both male and female students had the same level of attitudes towards the use of augmented reality applications in education. Similarly, Korucu, Gençtürk and Sezer (2016) and Sırakaya and Kılıç-Çakmak (2016) in their studies stated that attitudes of the students towards augmented reality practices were close to each other in terms of their gender. However, Onbaşılı (2018) found that attitudes of the female students towards augmented reality applications were more positive than the attitudes of the male students. Atasoy, Tosik-Gün and Kocamankaroğlu (2017) in their study found that the attitudes of male students towards the willingness to use the augmented reality applications were significantly higher than the attitudes of female students.

As a result, it was found that the augmented reality applications positively affect the attitudes of secondary school students towards the use of these applications in education and the students had positive opinions. In this context, it can be said that positive results can be achieved by applying augmented reality technologies in learning environments. In addition, it is thought that augmented reality applications can be an effective technology for teachers in planning the learning processes of their students according to the results of the study. 


\section{GíRiş}

Son yıllarda askeri, uzay ve tıp alanlarında kullanılmaya başlanan yeni teknolojilerin yansımaları eğitim alanında da kendisini göstermektedir. Bu teknolojilerin eğitim ortamlarda kullanılmalarında en dikkat çekici özellikleri, bireylerin öğrenmelerini kolaylaştırır, öğrenme ortamlarındaki etkinliklerini arttırır ve zengin öğrenme deneyimleri sağlar nitelikte olmalarıdır. Diğer taraftan bakıldığında da öğrenme ortamlarında meydana gelen değişimler, toplumların ihtiyaçları ve talepleri çerçevesinde ortaya çıkmaktadır (Odabaşı, 2010). Özellikle mevcut kullanımda bulunan yazılımsal ve donanımsal teknolojilerin çıktı olarak üç boyutlu olarak hale getirilmesi ile bireylerin kullanımlarına yönelik sanal ortamlar da oluşturulmaya başlanmıştır.

Augmented reality veya Türkçe karşılığı artırılmış gerçeklik (AR) olarak bilinen sanal ortamların geliştirilmesi ile eğitim ortamlarında da kullanılması düşünülen teknolojilerden birisi olarak karşımıza çıkmaktadır. Daha çok eğitim dışındaki alanlarda kullanılan bu ortamlardan birisi olan artırılmış gerçeklik uygulamaları (AG), bireylere gerçek dünya ile sanal dünyayı aynı mekân ve zaman diliminde deneyim sunmaktadır (Azuma, 1997). Bu özelliği ile AG ortamları bireylere gerçek yaşamdan kopmadan sanal dünya içerisinde güvenli bir yer sunabilmektedir. AG ortamlarında bireyler, gerçeklikten uzaklaşmadan yapılacak uygulamalarını gözlemleme, uygulaması tehlike yaratacak olay veya durumları güvenli şekilde yürütme, yeni karşılan farklı bir ortamı derinlemesine tanıma biçimindeki çeşitli yaşantıları gerçekleştirebilmektedirler (Atasoy, Tosik-Gün ve Kocaman-Karoğlu, 2017). Bununla birlikte Artırılmış gerçeklik (AG) kavramı bireyle ve kullanıcıları tarafından çoğu kez Sanal gerçeklik (SG) kavramı ile karıştırılmaktadır. Ancak bu kavramlarda ortak olarak bir sanallıktan bahsedilse de SG'de gerçeklikten tamamen soyutlanmış nesnelerin sanal ortamda bulunması söz konusu iken, AG'de ise nesneler dünya gerçekliğinde gerçek zaman diliminde ve mekânında yer almaktadır. Bu özelliği ile AG bireylere gerçek olma duygusunu çarpıcı bir şekilde sunabilmektedir (Kye ve Kim, 2008).

Artırılmış gerçeklik teknolojilerinin maliyetlerinin düşmesi ile bu teknolojilere erişilebilir ve kullanılabilir hale gelmesiyle öğretim ortamlarındaki potansiyelleri artmıştır (Somyürek, 2014). Artırılmış gerçeklik teknolojilerinin kullanımının eğitim ortamlarında giderek artmasını genç bireylerin onlara özgü bir takım özelliklerinden kaynaklandığından bahsedilmektedir. Kapil ve Roy (2014) Dijital nesil için, teknoloji odaklı bir yaşam istekleri olan, üretici sosyal medya kullanıcısı, ileri teknolojilerle donatılmış bir haberleşme ortamında yaşayan, karşılaştıkları sorunların üstesinden gelebilmek için teknolojiyi aktif olarak kullanabilen problemlerinin çözümünde teknolojiyi kullanabilecek yeterliklere sahip bireyler şeklinde bir tanımlamada bulunmaktadır. Bu özelliklere sahip bireylerin öğrenim süreçlerinde aktif katılım sağlayabilmeleri ve ilgilerinin artarak etkili kalıcı öğrenme deneyimleri kazanabilmeleri için onlara yönelik çoklu ortam materyallerinin oluşturulması ve öğretim ortamlarında işe koşulması gerekmektedir (Wang, Kim, Love ve Kang, 2013). Öğrenciler açısından bakıldığında ise öğretim etkinliklerinde artırılmış gerçeklik uygulamaları kullanılarak hazırlanan materyallerle etkileşim içerisinde bulunulması eğlenceli bir ortam oluşturmaktadır (i̇zgi Onbaşılı, 2018). Buna ek olarak El Sayed, Zayed ve Sharawy (2011) de geliştirdikleri Artırılmış gerçeklik öğrenci kartı (Augmented Reality Student Card), aracılı̆̆ıla öğrencilerin etkileşim içerisine girmelerini ve öğrenme materyallerini görselleştirmelerini sağlamışlardır. Ayrıca öğrencilerin anında geri bildirim aldıkları AG teknolojileri etkileşimleri sonucunda akademik başarılarının arttığı sonucu elde edilmiştir (Bacca, Baldris, Fabregat, Graf ve Kinshuk, 2014). Korucu, Gençtürk ve Sezer (2016) da belirtikleri üzere bireylerde aktif ve kalıcı öğrenme artırılmış gerçeklik teknolojilerinin sınıf ortamlarında daha çok görülür hale gelmesi ve öğrenme sürecine katılması ile sağlanacağı öngörülmektedir. Alanyazın incelendiğinde artırılmış gerçeklik uygulamalarının birçok araştırmacının çalışma odağı olunmuştur.

Ibáñez, Di Serio, Villarána ve Kloosa (2014), artırılmış gerçeklik uygulamasının öğrenme üzerindeki etkisini inceledikleri çalışmada 64 lise öğrencisi ile elektromanyetizmanın temel kavramlarıyla ilgili artırılmış gerçeklik tabanlı materyal tasarlamışlardır. Çalışmada artırılmış gerçeklik uygulamasının öğrencilere etkili öğrenme ortamı sağladığını belirtmişlerdir. Küçük, Yılmaz ve Göktaş (2014), artırılmış gerçeklik uygulamalarının öğrencilerin akademik başarılarına ve tutumlarına ilişkin etkisini belirlemek amacıyla yaptıkları çalışmalarında, 122 ortaokul öğrenci katılmıştır. İngilizce dersinin artırılmış gerçeklik uygulamalarıyla desteklenen bu çalışmada, ortaokul öğrencilerinin tutumları olumlu olduğu görülmüştür. Tutum ölçeğinin al boyutlarında (kullanma memnuniyeti, kullanma kaygısı, kullanma isteği) ortaokul öğrencileri artırılmış gerçeklik uygulamalarından memnun kaldıkları, kullanma kaygıların az olduğunu ve artırılmış gerçeklik uygulamalarını kullanmak islediklerini belirtmişlerdir.

Bir başka çalışmada ilkokul 4. sınıf düzeyinde 57 öğrenci ile sorgulayıcı öğrenme deneyimleri ile "su bitkileri" konusunda mobil AG aracılığıyla Chiang, Yang ve Hwang (2014), öğrencilerin başarılarını ve motivasyonlarını incelemişlerdir. Yürütülen çalışma sonucunda, mobil AG uygulamasının öğrencilerin başarılarını arttırdığı ve motivasyona yönelik alt boyutlar puanlarının AG kullanılmayan gruba göre yüksek düzeyde olduğu görülmüştür. Ersoy, Duman ve Öncü (2016) çalışmalarını Bursa'daki bir ortaokulda 5. ve 6. sınıf düzeyindeki 26 öğrenci (14 kız, 12 erkek) ile "Görsel Tasarım Illkeleri” konusuna yönelik bir öğretim faaliyeti olarak desenlemişlerdir. Yarı deneysel desenlerden "seçkisiz sadece son test kontrol grubu deseni” yöntemi kullanılan çalışmada rastgele deney ve kontrol grubu şeklinde iki grup oluşturulmuş ve yapılan uygulama sonunda son test verilmiştir. Deney grubundaki öğrencilerden artırılmış gerçeklik teknolojisi ile hazırlanan materyalleri kullanmaları istenirken; kontrol grubundaki öğrencilere masaüstü bilgisayarlarda kullanılan benzer nitelikteki uygulamaları kullanmaları istenmiştir. Tasarlanan deneysel uygulamanın sonunda her iki gruba da başarı testi verilmiştir. Buna ek olarak gerçekleştirilen deneysel sürecin öğrenciler açısından etkileşim, fayda ve kavrama noktasında etkililiğini ölçmek amacıyla motivasyon ölçeği uygulanmıştır. Yapılan çalışmadan elde edilenlere göre, artırımış gerçeklik materyalleri aracılığıyla yürütülen öğretim faaliyetinin, öğrencilerin motivasyon ve başarılarını olumlu olarak etkilediği görülmüştür. 
Korucu, Gençtürk ve Sezer (2016) çalışmalarına eğitim ortamlarında artırılmış gerçeklik teknolojilerinin etkinliğini ve okullarda yaygınlaştırılması amacıyla başlamışlar, bilişim teknolojileri dersinde artırılmış gerçeklik uygulamalarının 5. ve 6. Sınıf ortaokul öğrencilerinin başarı ve tutumlarına etkisini incelemişlerdir. Çalışmaya katılan 120 ortaokul öğrencisine ilk olarak artırımış gerçeklik uygulamalarının nasıl çalıştığı gösterilmiş sonrasında öğrencilere hangi uygulamalar olduğu gösterilerek, öğrencilerin bu uygulamaları kullanmaları sağlanmıştır. Sırakaya ve Kılıç-Çakmak (2016) yaptıkları çalışmalarında ortaokul öğrencilerinin artırılmış gerçeklik uygulamalarına yönelik tutumlarını ve farklı değişkenlerden açısından değişimlerini incelemeyi amaçlamışlardır. Çalışmaya katılan 7.sınıfta öğrenim gören 54 ortaokul öğrencisine Fen ve Teknoloji dersindeki Güneş Sistemi ve Ötesi: Uzay Bilmecesi ünitesi araştırmacılar tarafından geliştirilmiş artırılmış gerçeklik uygulaması aracılığıyla artırılmış gerçeklik deneyimi yaşamaları için verilmiştir. Çalışmanın veri toplama araçlarını kişisel bilgi formu ve artırılmış gerçeklik uygulamalarına yönelik geliştirilmiş bir tutum ölçeği meydana getirmiştir. Elde edilen verilerden, ortaokul öğrencilerinin derste kullanılan artırılmış gerçeklik uygulamalarına karşı olumlu bir tutum sahibi oldukları sonucuna varılmıştır. Diğer yandan bu tutumun cinsiyet, kişisel bilgisayar sahibi olup olmama ve taşınabilir cihaz sahibi olup olmama değişkenleri açısından anlamlı olarak farklılaşmadığı görülmüştür. Ancak bilgisayar oyunu oynama sıklığı değişkeni açısından, nadiren oyun oynayan öğrencilerin çok sık oynayanlara göre daha yüksek düzeyde olumlu tutum sahibi oldukları sonucuna varılmıştır.

Yıldırım (2016) artııımış gerçeklik uygulamalarının 6. sınıf öğrencilerin tutumlarına etkisini incelediği çalışmada, Fen Bilimleri dersinin Maddenin Tanecikli Yapısı Ünitesi için ABCArTablet ve ABCArPC artırılmış gerçeklik uygulaması geliştirmiştir. Toplam 50 öğrenci ile yürütülen bu deneysel çalışmada öğrencilerin tutumları arasında anlamı bir farklık bulunmamıştır. Ancak grupların kendi içerisinde yapılan uygulama öncesi tutum ve uygulama sonrası tutum puanları arasında anlamlı farklılık bulunmuştur. Bu farklılığın deney 1 gurup lehine olduğu belirtilmiştir. Ayrıca öğrenciler ile yapılan görüşmelerde artırılmış gerçeklik uygulamasının, dersi daha eğlenceli kıldığını, derse karşı ilginin arttırdığını ve diğer derslerde kullanılmasını istediklerini belirtmişlerdir. Artırılmış gerçeklik uygulamasına yönelik öğretmen görüşü ise, derse karşı öğrencilerin ilgisini arttırdığını ve kolay öğrenme sağladığını ifade etmiştir. Atasoy, Gün Tosik ve Kocaman Karoğlu (2017) yaptıkları deneysel çalışmada toplam 38 ortaokul 8. sınıf öğrencilerin artırılmış gerçeklik ortamlarına ilişkin tutumlarını ve güdülenmelerini incelemişlerdir. Çalışma sonucunda ortaokul öğrencilerin artırılmış gerçeklik ortamlarına yönelik tutumlarının yüksek olduğu belirtilmiştir. Çalışmada hem erkek hem de kadın öğrencilerin aynı tutum düzeyine sahip oldukları sonucuna varmışlardır. Ayrıca çalışmada tutum ve güdüleneme arasında yüksek düzeyde ve pozitif yönde bir ilişki bulgulamıştır. Sırakaya, M. ve Alsancak Sırakaya, D. (2018). Yarı deneysel desen olarak yaptıkları çalışmada artırılmış gerçeklik kullanımının tutum ve motivasyona etkisini incelemişlerdir. Fen eğitiminde gerçekleştirilen bu çalışma, toplam 87 ortaokul 7. sınıf öğrencisiyle yürütülmüştür. Çalışma sonucunda öğrencilerin fen öğrenmesinde artırılmış gerçeklik kullanımının tutumlarını olumlu yönde etkilediği ve motivasyonlarını artırdığı görülmüştür.

Ramazanoğlu ve Aker (2019) pedagojik formasyon eğitimi programında öğrenim gören ve Öğretim Teknolojileri ve Materyal Tasarımı dersini alan 20 öğretmen adayı ile nitel araştırma yöntemi kullanılarak desenledikleri artırılmış gerçeklik teknolojisinin eğitim amaçı kullanımına ilişkin görüşlerini araştırmışlardır. Veri toplama aracı olarak yarı yapılandırılmış görüşme formu kullanmış ve betimsel analiz yöntemiyle analiz gerçekleştirilmiştir. Öğretmen adayları artırılmış gerçeklik uygulamalarıyla ilgili olarak en sık sırasıyla ilgi çekmesi, kalıcı öğrenmeyi sağlaması ve motivasyonu artıracağı, hayat ve gerçek hayat ile ilişkilendirmeleri kolaylaştıracağı, eğitime faydalı olacağı, kalıcılığı olumlu yönde etkileyeceği ve dikkat çekeceği görüşlerinde bulunmuşlardır. Araştırmada artırılmış gerçeklik uygulamalarının öğrencilerin bilişsel, duyuşsal ve psiko-motor öğrenme alanlarına hitap ettiğinden öğrenmeyi kolaylaştıracağını, derse katılımının artıracağı sonuçları elde edilmiştir. Ayrıca eğitim alanından farklı olarak sağlık, oyun ve eğlence gibi alanlarda da çalışmalar yapılabileceği önerilerinde bulunmuşlardır. Bal'ın (2018) çalışmasında da ortaya koyduğu üzere artırılmış gerçeklik konusunda yapılan çalışmalarda cihaz olarak çoğunlukla bilgisayar, kamera, cep telefonu ve tablet pc kullanıldığı, yazılım olarak 3D Tasarım Yazılımı, QR Code benimsendiği, araştırma metodu olarak nicel ve karma metodların tercih edildiği, tarama ve tam deneysel desenlerde çalışmaların yürütüldüğü, araştırma grubu olarak üniversite öğrencileri ve ortaokul öğrencilerinin seçildiği görülmüştür.

Bu çalışmayla birlikte artırılmış gerçeklik teknolojilerinin eğitim ortamlarındaki varlığı ve etkili kullanılabilirliği araştırılmak istenmektedir. Çalışma grubu olan ortaokul öğrencilerinin artırılmış gerçekliğe ilişkin tutumları ve bu teknolojilere ilişkin görüşleri merak konusu olmuştur. Alanyazındaki çalışmalarda AG teknolojilerinin derslerde kullanılmasının öğrencilerin derse yönelik ilgi, merak ve isteğini artırdığı, AG'ye yönelik tutumlarının olumlu olduğu ve derse yönelik güdülenme ve motivasyonlarını arttırdığı yönündeki bulgular konuyu araştırmaya değer kılmaktadır. Bundan hareketle bu araştırmanın amacı, ortaokul öğrencilerinin artırılmış gerçeklik uygulamalarının eğitimde kullanımına yönelik tutumlarını incelenmektir. Bu doğrultuda aşağıda sunulan sorulara yanıt aranmıştır.

- Öğrencilerinin artırılmış gerçeklik uygulamalarına yönelik tutum düzeyleri nasıldır?

- Öğrencilerinin artırılmış gerçeklik uygulamalarına yönelik tutumlarının cinsiyete göre farklılık göstermekte midir?

- Artırılmış gerçeklik uygulamalarının öğrencilerin tutum düzeylerini nasıl etkilemiştir?

- Artırılmış gerçeklik uygulamalarının eğitim sürecine nasıl bir katkı getirmektedir?

| Kastamonu Eğitim Dergisi, 2020, Vol. 28, No. 4 | 


\section{Araştırma Deseni}

Ortaokul öğrencilerinin artııımış gerçeklik uygulamalarına yönelik tutumlarını inceleyen bu araştırmada karma model yöntemlerinden Eşzamanlı üçgenleme tasarım kullanılmıştır. Karma yöntem, yapılan çalışma içerisinde nitel ve nicel yöntemin bileştirilmesi olarak tanımlanmaktadır (Creswell, 2003). Karma yöntem, yapılan araştırmalarda farklı yöntem ve stratejileri kullanarak toplanan çoklu verileri bir bütün içerisinde sunma ve analiz etme yöntemidir (Johnson ve Turner, 2003). Eşzamanlı üçgenleme tasarımında nicel ve nitel veriler ikisi bir arada toplanıp analiz edilir. Veri analizi her iki yöntemde ayrı ayır yapılır ve yorumlamada birleştirme gerçekleşir. Bu Eşzamanlı üçgenleme tasarımı, araştırmada elde edilen bulguları doğrulamak ve güçlendirmek için faydalıdır (Creswell, 2003).

Araştırmada nicel araştırma yöntemlerinden öntest-sontest tek gruplu zayıf deneysel desen kullanılmıştır. Zayıf deneysel araştırmaları, gerçek araştırmaların uygulanması zor olan durumlarda kullanılan bir desenidir. Bu desende rastgele seçilen tek grup üzerinde test edilir. Seçilen aynı denek grubuna uygulama öncesi ve uygulama sonrası aynı ölçme aracı kullanılır (Karasar, 2012). Uygulama sürecinde çalışma grubunun artııımış gerçeklik uygulamalarına yönelik tutumlarını göstermek için uygulamanın başında ve bitiminde veriler toplanmıştır. Araştırmada nitel araştırma yöntemi olarak ise, betimsel analiz yöntemi kullanılmıştır. Betimsel analiz, çalışmak istenilen farklı olgu ve olaylar ilişkin bilgi elde edebilmek için sıklıkla başvurulan yöntemlerden birisidir (Büyüköztürk, Çakmak, Akgün, Karadeniz ve Demirel, 2010).

\section{Katılımcı Grubu}

Gönüllü katılım esas olan bu araştırmanın katıımcılarını, 2018-2019 eğitim-öğretim yılında Siirt ilinde bulunan bir ortaokulun 6. sınıfında öğrenim gören 44 öğrenci oluşturmaktadır. Çalışma gurubunun seçiminde uygun örnekleme yöntemi kullanılmıştır. Uygun örneklem, problem ile ulaşılmak istenilen problem ile ilişkin kolay ulaşılabilir bireylerin belirlenmesi yöntemidir (Büyüköztürk ve diğerleri, 2010). Katılımcıların demografik özelikleri tablo 1'de gösterilmiştir.

\section{Tablo 1. Katılımcıların demografik özelikleri}

\begin{tabular}{lcc}
\hline Cinsiyet & $\mathrm{N}$ & $\%$ \\
\hline Kadın & 16 & 36,4 \\
Erkek & 28 & 63,6 \\
\hline
\end{tabular}

Tablo 1 incelendiğinde katılımcıların katılan 44 öğrenciden 16'sı $(\% 36,4)$ kadın, $28^{\prime} i$ erkek $(\% 63,6)$ öğrencidir. Ayrıca ölçüt olarak araştırmaya katılan öğrenciler içerisinde tutumu en yüksek \%25'lik gurup ile görüşmeler yürütülmüştür.

\section{Uygulama Süreci}

Çalışmanın uygulama aşamasında 6. sınıf Sosyal Bilgiler dersi öğretim programının 7. ünitesindeki elektronik yüzyıl nükleer enerjiler konusuna yönelik araştırmacı tarafından 3 boyutlu (3B), 2 boyutlu (2B) animasyon ve video materyalleri tasarlanmıştır. Bu süreçte materyal hazırlamada Unity 3D yazılımından faydalanılmıştır. Tasarlanan materyaller QR kodlar oluşturularak öğrencilerin kullanımına sunulmuştur. Öğrenciler, Cardboard sanal gözlükleri ile hazırlanan materyallerle etkileşime girmişlerdir. Hazırlanan materyaller ders öğretmenleri tarafından toplam beş hafta (20 saat) boyunca ders içerisinde kullanılmıştır. Çalışmada yürütülen uygulama boyunca kullanım rahatlığı ve ulaşılabilirlik özellikleri nedeniyle mobil cihazlardan akıllı telefon uygulama aracı olarak seçilmiştir.

\section{Veri Toplama Araçları}

Nicel bölümde araştırmaya katılan denek gurubunun artııımış gerçeklik uygulamalarına karşı tutumlarının belirlenmesi için uygulama öncesinde ve uygulama sonrasında Küçük, Yılmaz, Baydaş ve Göktaş (2014) tarafından geliştirilen ve kullanmaya ilişkin "memnuniyet", "kaygı" ve "istek" boyutlarından oluşan "Artırılmış Gerçeklik Uygulamaları Tutum Ölçeği" kullanılmıştır. Ölçekte, birinci boyutta 7 olumlu ifade, ikinci boyutta 6 olumsuz ifade, üçüncü boyutta 2 olumlu ifade yer almaktadır. Ölçeğin Cronbach alfa güvenirlik katsayısı (Ölçeğin tümü $\alpha=.835$; 1 . boyut $\alpha=.862 ; 2$. boyut $\alpha=.828$; 3 . boyut $\alpha=.644$ ) olarak bulmuştur. Bu çalışmada ise Cronbach alfa güvenirlik katsayısı öntest için (Ölçeğin tümü $\alpha=.774$; 1 . boyut $\alpha=.892 ; 2$. boyut $\alpha=.726$; 3. boyut $\alpha=.842$ ), sontest için (Ölçeğin tümü $\alpha=.879 ; 1$. boyut $\alpha=.897 ; 2$. boyut $\alpha=.816 ; 3$. boyut $\alpha=.857$ ) olarak bulunmuştur.

Nitel bölümde ise yarı yapılandırılmış görüşme formu kullanılmıştır. Bu form için soru havuzu oluşturulmuş ve bu soruların kapsam geçerliğinin sağlanabilmesi amacıyla Türkçe ve Bilgisayar ve Öğretim Teknolojileri Eğitimi alanlarında görev yapan 3 uzman görüşüne sunulmuş, uzman görüş önerileri doğrultusunda formda 2 soruya yer verilmiştir. Görüşmelerde ses kayıt cihazı kullanılmıştır. Ayrıca görüşmelerde araştırmacı tarafından notlar alınmıştır.

\section{Verilerin Analizi}

Nicel verilerin analizinde araştırmaya katılan deney gurubunun artııımıs gerçeklik uygulamalarına karşı tutumlarının belirlenmesi için SPSS 21 programı kullanılmıştır. Verilerin homojenliğini test etmek için Kolmogorov-Smirnov prosedürü kullanılmıştır. Kolmogorov-Smirnov testi sonucunda normal dağııım göstermeyen verilerin cinsiyet bağımsız değişkenine göre ortalama karşılaştırmalarına ilişkin Mann-Whitney $U$ testi ve öntest-sontest verilerin puanları arasındaki farkı ortaya çıkarmak için 
Wilcoxon testi kullanılmıştır. Artırılmış Gerçeklik Uygulamaları Tutum Ölçeğinin istatistiksel puanlarının yorumlanmasında aşağıdaki prosedür uygulanmıştır.

Kesinlikle katılmıyorum için $(1.00 \leq \bar{X} \leq 1.79)$

Katılmıyorum için $(1.80 \leq \bar{X} \leq 2.59)$

Kararsızım $(2.60 \leq \bar{X} \leq 3.39)$

Katılıyorum için $(3.40 \leq \bar{X} \leq 4.19)$

Kesinlikle katılıyorum için $(4.20 \leq \bar{X} \leq 5.00)$

Nitel verilerin analizinde betimsel analizi yöntemi ile yapılmıştır. Bu analiz türünde araştırmacı görüşme yaptığın çalışma grubun görüşlerini doğrudan alıntılara yer vermektedir (Yıldırım ve Şimşek, 2003). Görüşmelerde ses kayıt cihazındaki kayıtları yazılı olarak dijital ortama aktarılmıştır. Araştırmaya katılan öğretmen adaylarının isimleri Ö1, Ö2 gibi isimlendirilmiştir.

\section{BULGULAR}

Bu bölümde ulaşılan bulgular yer almaktadır. İlk önce katılımcıların gerçeklik uygulamalarına yönelik tutumlarının düzeyleri, sonra verilerin normal dağılım gösterip göstermediğine ilişkin bulgulara, daha sonra nicel verilerin analizine ilişkin bulgulara, son olarak sonra nitel verilerin analizine ilişkin bulgular yer verilmiştir. Ortaokul öğrencilerinin uygulama öncesi ve uygulama sonrasında artırılmış gerçeklik uygulamalarına yönelik tutum ölçeğindeki faktörlere ilişkin analiz sonuçları Tablo 2'de sunulmuştur.

Tablo 2. Öğrencilerinin artırılmış gerçeklik uygulamalarına yönelik tutum düzeyleri (faktörlere ilişkin analiz sonuçları)

\begin{tabular}{|c|c|c|c|c|c|c|}
\hline Faktörler & Maddeler & $\mathrm{N}$ & ÖnTest $\bar{X}$ & ÖnTest SS & Son Test $\bar{X}$ & Son Test SS \\
\hline \multirow{7}{*}{ Kullanıma Memnuniyeti } & M1 & 44 & 4,11 & 1,315 & 4,40 & ,947 \\
\hline & M4 & 44 & 3,79 & 1,373 & 4,15 & 1,379 \\
\hline & M5 & 44 & 3,54 & 1,421 & 4,11 & 1,333 \\
\hline & M7 & 44 & 4,20 & 1,132 & 4,31 & 1,176 \\
\hline & M9 & 44 & 3,75 & 1,496 & 4,31 & 1,234 \\
\hline & M11 & 44 & 4,11 & 1,261 & 4,43 & 1,108 \\
\hline & M15 & 44 & 4,02 & 1,422 & 4,52 & 976 \\
\hline \multirow{6}{*}{ Kullanıma Kaygısı } & $\mathrm{M} 2$ & 44 & 2,04 & ,963 & 1,59 & 897 \\
\hline & M3 & 44 & 2,04 & ,913 & 1,47 & ,628 \\
\hline & M6 & 44 & 2,04 & ,805 & 1,54 & ,847 \\
\hline & M8 & 44 & 2,09 &, 563 & 1,54 & ,729 \\
\hline & M10 & 44 & 2,02 & ,731 & 1,54 & 847 \\
\hline & M14 & 44 & 2,15 & ,775 & 1,65 & ,913 \\
\hline \multirow{2}{*}{ Kullanıma İsteği } & M12 & 44 & 3,20 & ,851 & 4,52 & 976 \\
\hline & M13 & 44 & 3,13 & 1,025 & 4,56 & ,949 \\
\hline
\end{tabular}

Tablo 2 incelendiğinde katılımcıların artırılmış gerçeklik uygulamalarını kullanma memnuniyeti ön test ortalamalarının (M= $3,93)$ olduğu, son test ortalamalarının $(M=4,32)$ şeklinde arttığı gözlenmiştir. Kullanma kaygısı ön test ortalamalarının $(M=2,05)$ olduğu, son test ortalamalarının $(M=1,56)$ şeklinde arttığı gözlenmiştir. Kullanma isteği ise, ön test ortalamalarının $(M=3,17)$ olduğu, son test ortalamalarının 4,54 şeklinde arttığı gözlenmiştir. Elde edilen verilerin homojenlik dağılımına ilişkin KolmogorovSmirnov testi bulguları tablo 3'te sunulmuştur.

Tablo 3. Kolmogorov-Smirnov test bulguları

\begin{tabular}{|c|c|c|c|c|}
\hline \multirow{2}{*}{ Test } & \multirow{2}{*}{ Faktörler } & \multicolumn{2}{|c|}{ Kolmogorov Smirnov(a) } & \multirow{2}{*}{ DF } \\
\hline & & $\mathrm{S}$ & $\mathrm{P}$ & \\
\hline \multirow{3}{*}{ 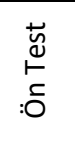 } & 1. Faktör & ,156 & ,000 & \multirow{6}{*}{44} \\
\hline & 2. Faktör & ,363 & ,000 & \\
\hline & 3. Faktör & 191 & ,000 & \\
\hline \multirow{3}{*}{ 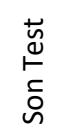 } & 1. Faktör & ,242 & ,000 & \\
\hline & 2. Faktör & 193 & ,000 & \\
\hline & 3. Faktör & ,398 & ,000 & \\
\hline
\end{tabular}

Tablo 3 incelendiğinde veri dağılımlarının normal dağılım göstermediği belirlenmiştir. Dolasıyla analizlerde parametrik olmayan istatiksel yöntemler kullanılmıştır. Katılımcıların artıılmış gerçeklik uygulamalarına yönelik tutumlarının cinsiyete bağımsız değişkenine ilişkin Mann-Whitney U testi bulguları tablo 4 'te gösterilmiştir. 
Tablo 4. Katılımcıların artırımış gerçeklik uygulamalarına yönelik tutumlarının cinsiyete göre Mann-Whitney U test bulguları

\begin{tabular}{|c|c|c|c|c|c|c|c|c|}
\hline Test & Fak & rler & Cinsiyet & $\mathrm{N}$ & Sıra Ortalaması & Sıra Toplamı & $U$ & $P$ \\
\hline \multirow{6}{*}{ 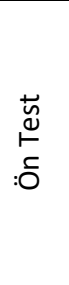 } & \multirow{2}{*}{1.} & \multirow{2}{*}{ Faktör } & Kadın & 16 & 20,88 & 334,00 & \multirow{2}{*}{198,000} & \multirow{2}{*}{,521 } \\
\hline & & & Erkek & 28 & 23,43 & 656,00 & & \\
\hline & \multirow{2}{*}{2.} & \multirow{2}{*}{ Faktör } & Kadın & 16 & 22,25 & 356,00 & \multirow{2}{*}{220,000} & \multirow{2}{*}{ 914 } \\
\hline & & & Erkek & 28 & 22,64 & 634,00 & & \\
\hline & \multirow{2}{*}{3.} & \multirow{2}{*}{ Faktör } & Kadın & 16 & 21,28 & 340,50 & \multirow{2}{*}{204,500} & \multirow{2}{*}{,623 } \\
\hline & & & Erkek & 28 & 23,20 & 649,50 & & \\
\hline \multirow{6}{*}{ 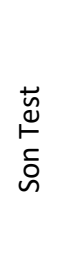 } & \multirow{2}{*}{1.} & \multirow{2}{*}{ Faktör } & Kadın & 16 & 20,31 & 325,00 & \multirow{2}{*}{189,000} & \multirow{2}{*}{ 369 } \\
\hline & & & Erkek & 28 & 23,75 & 665,00 & & \\
\hline & \multirow{2}{*}{2.} & \multirow{2}{*}{ Faktör } & Kadın & 16 & 25,72 & 411,50 & \multirow{2}{*}{172,500} & \multirow{2}{*}{ 196 } \\
\hline & & & Erkek & 28 & 20,66 & 578,50 & & \\
\hline & \multirow{2}{*}{3.} & \multirow{2}{*}{ Faktör } & Kadın & 16 & 22,53 & 360,50 & \multirow{2}{*}{223,500} & \multirow{2}{*}{ 988 } \\
\hline & & & Erkek & 28 & 22,48 & 629,50 & & \\
\hline
\end{tabular}

Tablo 4'deki verilere göre, katılımcıların artırılmış gerçeklik uygulamalarına yönelik tutum ölçeğinin faktörlerinin ön ve son test ortalamalarının cinsiyete bağımsız değişkenine göre anlamlı bir şekilde farklılaşmamaktadır(p>0,05). Artırılmış gerçeklik uygulamalarının öğrencilerin tutum düzeylerine etkisine ilişkin Wilcoxon Test bulguları tablo 5'de sunulmuştur.

Tablo 5. Artırımış gerçeklik uygulamalarının öğrencilerin tutum düzeylerine etkisi (Wilcoxon Test bulguları)

\begin{tabular}{|c|c|c|c|c|c|}
\hline Son test - Ön test & Siralar & $\mathrm{N}$ & Sıra Ortalaması & Sıra Toplamı & $\mathrm{P}$ \\
\hline & Negatif Sıra & 13 & 21,23 & 276,00 & \\
\hline \multirow[t]{2}{*}{1.} & Pozitif Sıra & 26 & 19,38 & 504,00 & 112 \\
\hline & Eşit & 5 & - & - & \\
\hline & Negatif Sıra & 28 & 23,64 & 662,00 & \\
\hline \multirow[t]{3}{*}{ Faktör } & Pozitif Sıra & 11 & 10,73 & 118,00 & ,000 \\
\hline & Eşit & 5 & - & - & \\
\hline & Negatif Sıra & 5 & 9,20 & 46,00 & \\
\hline \multirow[t]{2}{*}{ 3. Faktör } & Pozitif Sıra & 36 & 22,64 & 815,00 & ,000 \\
\hline & Eşit & 3 & - & - & \\
\hline
\end{tabular}

Tablo 5'te elde edilen betimsel analiz sonuçlarına göre, katılımcıların artırılmış gerçeklik uygulamalarına yönelik tutumlarının kullanma memnuniyeti faktöründe ön ve son test puan ortamalar arasında anlamı bir fark $(p>0,05)$ bulunmamıştır. Kullanma kaygısı faktöründe uygulama öncesi ve uygulama sonrası puan ortamalar arasında anlamı bir fark $(p<0,05)$ bulunmuştur. Sıra ortalamaları ve toplamları dikkate alındığından, bu farkın negatif sıralar puan lehinde olduğu belirtilmiştir. Kullanma isteği faktöründe ise ön ve son test puan ortamalar arasında anlamı bir fark $(p<0,05)$ bulunmuştur. Sıra ortalamaları ve toplamları dikkate alındığından, bu farkın pozitif sıralar, lehinde olduğu ortaya çıkmıştır. Katılımcıların artırılmış gerçeklik uygulamalarının eğitim sürecine katkısına ilişkin görüşleri tablo $6^{\prime}$ da sunulmuştur.

Tablo 6. Artırımış gerçeklik uygulamalarının eğitim amaçlı kullanımı

\begin{tabular}{|c|c|c|c|c|}
\hline \multirow{2}{*}{ Tema } & \multicolumn{2}{|c|}{ Olumlu } & \multicolumn{2}{|c|}{ Olumsuz } \\
\hline & Kategori & $\mathrm{N}$ & Kategori & $\mathrm{N}$ \\
\hline \multirow{15}{*}{ Eğitime Katkı } & Etkin katılım & 11 & Bağımlılık & 3 \\
\hline & Kalıcılı öğrenme & 10 & Zaman alıcı & 2 \\
\hline & Dikkat artırma & 9 & Odaklanamama & 2 \\
\hline & Görsellik & 9 & Sıkılma & 1 \\
\hline & İlgi çekici & 9 & & \\
\hline & Eğlenceli & 8 & & \\
\hline & Kolay öğrenme & 8 & & \\
\hline & Motivasyon & 8 & & \\
\hline & Derslerde kullanma & 8 & & \\
\hline & Gerçeklik hissi & 8 & & \\
\hline & Farklılık & 7 & & \\
\hline & Verimlilik & 7 & & \\
\hline & Aktif katılım & 7 & & \\
\hline & Faydalı & 6 & & \\
\hline & Pekiştirme & 5 & & \\
\hline
\end{tabular}

Tablo 6'ya bakıldığında katılımcıların artııımış gerçeklik uygulamalarının eğitim amaçlı kullanımına ilişkin olumlu görüşlerinde; 11 öğrenci derslere etkin katılım sağlayacağı, 10 öğrenci kalıcılığı arttıracağı, 9 öğrenci dikkat arttıracağı, dersi görsel olarak işlemede yardımcı olacağı ve ilgi çekeceğini, 8 öğrenci eğlenceli olduğu, öğrenmeyi kolaylaştıracağı, motivasyon arttıracağı, derslerde kullanmak istediklerini ve gerçeklik hissi oluşturacağını, 7 öğrenci farklılık yaratacağı, verimli olacağı ve aktif katılım 
sağlayacağı, 6 öğrenci derslerde kullanması faydalı olacağı ve 5 öğrenci konuları pekiştirmeye yardımcı olacağı görüşünde bulunmuşlardır. Katılımcılardan elde edilen bulguları örneklemesi için bazı katılımcıların ifadelerine yer verilmiştir.

Ö2: “...konuyu daha pekiştirmemize yardımcı olacağını düşünüyorum”

Ö3: "... artırılmış gerçeklik uygulaması eğlenceli ve ilgimizi çektiği için bilgiler daha kalıcı oluyor"

Ö5: “... Biraz da görüntülü bir şey kullanılması insanların daha çok zihninde kalır..."

Ö6: "...insanın ilgisini çeker hem de insan zihninde daha iyi kalır"

Ö8: “...eğer kullanılırsa ders daha ilgi çekici olup ders dinlenilir... dersler daha verimli geçer..."

Ö9: "Derslerde kullanılmasını isterim çünkü derse daha aktif katılım olur..."

Ö10: "...kullanmak isterim çünkü ilgimiz daha çok artar derslere odaklanabiliriz daha çok heves olur gerçekleri anlayabiliriz daha iyi"

Katılımcıların artırılmış gerçeklik uygulamalarının eğitim amaçlı kullanımına ilişkin olumsuz görüşlerinde; 3 öğrenci bağımlılık yaratacağını, 2 öğrenci zaman alıcı olduğunu, 2 öğrenci odaklanmada sorun yaratacağı ve 1 öğrenci sıkıldığını belirtmiştir. Katılımcılardan elde edilen bulguları örneklemesi için bazı katılımcıların ifadelerine yer verilmiştir.

Ö6: "... ama ben bazen sıkıldım ve çok zaman alıyor..."

Ö4: "...çünkü en ufak bir şeyde dikkatin dağılıyor"

Ö11: "...ama olumsuz yanı teknolojiye bağımlılık artar".

Ö10: "...bağımlı kalırsak belki kötü olur"

\section{TARTIŞMA}

Bu çalışmada ortaokul öğrencilerinin artırılmış gerçeklik uygulamalarının eğitimde kullanımına yönelik tutumlarının incelenmesi amaçlanmıştır. Bu amaç çerçevesinde ortaokul öğrencilerinin artırılmış gerçeklik uygulamalarının eğitimde kullanımına yönelik kullanma memnuniyetlerinin yüksek olduğu, kullanıma kaygılarının az olduğu ve kullanma isteklerinde kararsız kaldıkları tespit edilmiştir. Ancak çalışmada artırımış gerçeklik uygulamalarının eğitimde kullanımına yönelik öğrencilerin tutum düzeylerini etkilediği görülmüştür. Buna göre öğrencilerinin artırılmış gerçeklik uygulamalarının eğitimde kullanımına yönelik kullanma kaygılarının azaldığını ve kullanma isteklerinin arttığı sonucuna varılmıştır. Öte yandan öğrencilerinin artırılmış gerçeklik uygulamalarının eğitimde kullanımına yönelik kullanma memnuniyetlerinin arttığı, ancak istatiksel olarak anlama bulunmamıştır. Bu durumların muhtemel nedenleri ise: artırılmış gerçeklik uygulamalarının eğitim amaçlı kullanılmasında; derslere etkin katılım sağlanacağı, kalıcılığı arttıracağı, dikkat arttıracağı, ilgi çekeceğini, derslerin daha eğlenceli olacağı, öğrenmeyi kolaylaştıracağı, motivasyon arttıracağı, gerçeklik hissi oluşturacağını, farklılık yaratacağı, verimli olacağı, derslerde aktif katılım sağlayacağı, derslerde kullanması faydalı olacağı ve konuları pekiştirmeye yardımcı olabileceğinden kaynaklandığı söylenebilir. Nitel verilerde öğrenciler benzer görüşler belirtmişlerdir. Benzer şekilde Di Serio, Ibanez ve Kloos (2013) artırılmış gerçeklik uygulamalarının öğrencilerin öğrenmeye ilişkin tutum ve motivasyonlarını etkilediğini bulmuşlardır. Küçük, Yılmaz ve Göktaş (2014) yaptıkları çalışmada yedi okulun beşinci sınıf ortaokul öğrencilerin, artırılmış gerçeklik uygulamalarından memnun kaldıkları, kullanma kaygılarının azaldığını ve diğer derslerde kullanmak istedikleri belirtilmiştir. Ibáñez, Di Serio, Villarána ve Kloosa (2014) 64 lise öğrencisiyle yürüttükleri deney çalışmada artırılmış gerçeklik uygulamalarının etkili öğrenme sağladığı sonucuna varmışlardır. Chiang, Yang ve Hwang (2014) kuzey Tayvan'daki dördüncü sınıf öğrencileri ile yürüttükleri deneysel çalışmada mobil artırılmış gerçeklik uygulamalarının öğrencilerin motivasyonlarını yükselttiğini ifade etmişleridir. İzgi Onbaşılı (2018) çalışmasında artırılmış gerçeklik uygulamalarının dördüncü sınıf öğrencilerin tutum ve motivasyonlarını anlamı bir şekilde etkilediği sonucuna varılmıştır.

Ayrıca artırılmış gerçeklik uygulamalarının sınıf ortamında kullanılması ilişkin öğrenciler; dersleri eğlenceli hala geldiğini, ilgilerin arttırdığını, öğrenmelerini kolaylaştırdığını ve diğer derslerde kullanılmasını istedikleri görüşünde bulunmuşlardır. Ramazanoğlu ve Aker (2019), artırılmış gerçeklik uygulamalarının öğrenme ortamında kullanılmasına ilişkin yaptıkları çalışmada, öğrenciler artırılmış gerçeklik uygulamalarının kullanımına ilişkin olumlu görüş belirtmişlerdir. Çalışma sonucundan farklı olarak Yıldırım (2016) çalışmasında artırılmış gerçeklik uygulamalarının kullanılması öğrencilerin tutumlarını etkilemediğini, öğrenciler artırılmış gerçeklik uygulamalarının öğrenmelerine katkı sağladığını, derslerin eğlenceli olduğunu ve başarılarının arttığı görüşünde bulunmuşlardır.

Çalışmada hem erkek öğrencilerin hem de kadın öğrencilerin artırılmış gerçeklik uygulamalarının eğitimde kullanıma ilişkin tutum düzeylerinin aynı seviyede olduğu görülmüştür. Aynı şekilde Korucu, Gençtürk ve Sezer (2016) ile Sırakaya ve Kılıç-Çakmak (2016) çalışmalarında öğrencilerin artırılmış gerçeklik uygulamalarına yönelik tutumlarının cinsiyete göre birbirine yakın olduğunu belirtmiştir. Farklı bir şekilde Onbaşılı (2018) çalışmasında artırılmış gerçeklik uygulamalarına yönelik kadın öğrencilerin tutumları erkek öğrencilerin tutumlarına göre daha olumlu olduğu görülmüştür. Atasoy, Tosik-Gün ve Kocamankaroğlu (2017) çalışmalarında ise artırılmış gerçeklik uygulamalarının kullanma isteğine yönelik erkek öğrencilerin tutumları kadın öğrencilerin tutumlarına göre daha anlamı olduğu bulunmuştur. 


\section{SONUÇ VE ÖNERILER}

Sonuç olarak artııımış gerçeklik uygulamalarının eğitimde kullanımına yönelik ortaokul öğrencilerinin tutum düzeylerini olumlu yönde etkilediğini ve görüşlerinin olumlu olduğu bulunmuştur. Bu bağlamda öğrenme ortamlarında artırılmış gerçeklik teknolojilerini uygulayarak olumlu sonuçlar alınabileceği söylenebilir. Ayrıca çalışma sonuçları öğrencilerin öğrenme süreçlerinin planlanmasında öğretmenler için etkili bir teknoloji olabileceği düşünülmektedir. Bu sonuçlar ışığında aşağıda araştırmaya ve uygulamaya yönelik öneriler sunulmuştur.

- Farklı eğitim kademelerindeki öğrencilerin artırılmış gerçeklik uygulamalarına yönelik tutumları incelenebilir.

- Bu çalışma Sosyal bilgiler dersinin elektronik yüzyıl nükleer enerjiler ünitesinde uygulanmıştır. Farklı dersler ve ünitelerde de AG uygulamaları kullanılabilir.

- Bu çalışmada öntest-sontest tek gruplu zayıf deneysel desen yöntemi kullanılmıştır. Illeride yapılacak çalışmalarda, artırıımış gerçeklik uygulamalarına yönelik tam deneysel çalışmalar yapılabilir

- Bu çalışmada öğrencilerinin artııılmış gerçeklik uygulamalarına yönelik tutumlarının cinsiyet bağımsız değişkenine göre farklılık gösterip göstermediği incelenmiştir. Gelecekte yapılacak çalışmalarda öğrencilerin artııııı̧̧ gerçeklik uygulamalarına yönelik tutumları farklı değişkenler açısından incelenebilir.

- Bu çalışmada artııımış gerçeklik uygulamalarının eğitimde kullanımına yönelik öğrencilerin tutum ve görüşlerinin olumlu yönde olduğu sonucuna varılmıştır. Öğrencilerin başarılarını ve motivasyonlarını artırmak için artırılmış gerçekliğe yönelik materyaller geliştirilebilir.

\section{KAYNAKÇA}

Atasoy, B., Tosik-Gün, E., \& Kocaman-Karoğlu, A. (2017). İlköğretim öğrencilerinin artırımış gerçeklik uygulamalarına karşı tutumlarının ve güdülenme durumlarının belirlenmesi. Journal of Kirsehir Education Faculty, 18(2), 435-448.

Azuma, R. (1997). A survey of augmented reality. Presence-Teleoperators and Virtual Environments, 6 (4), 355-385.

Bacca, J., Baldris, S., Fabregat, R., Graf, S., \& Kinshuk. (2014). Augmented reality trends in educaiton: a systematic review of research and applications. Educational Technology \& Society, 133-149.

Bal, E. (2018). The future of augmented reality and an overview on the to researches: a study of content analysis. Qual Quant 52, $2785-2793$. Erişim adresi: https://doi.org/10.1007/s11135-018-0705-x

Büyüköztürk, Ş., Kılıç-Çakmak, E., Akgün, Ö. E., Karadeniz, Ş., \& Demirel, F. (2010). Bilimsel araştırma yöntemleri (6. bs.). Ankara: Pegem Akademi.

Chiang, T. H., Yang, S. J., \& Hwang, G. J. (2014). An augmented reality-based mobile learning system to improve students' learning achievements and motivations in natural science inquiry activities. Journal of Educational Technology \& Society, 17(4), 352.365.

Creswell, J. W. (2003). Research design: qualitative, quantitative, and mixed methods approaches (2nd ed.). Thousand Oaks, CA: Sage.

Di Serio, A., Ibanez, M. B., \& Kloos, C. D. (2013). Impact of an augmented reality system on students' motivation for a visual art course. Computers \& Education, 68, 586-596.

El Sayed, N. A. M., Zayed, H. H., \& Sharawy, M. I. (2011). ARSC: Augmented reality student card. Computers \& Education, 56(4), $1045-1061$.

Ersoy, H., Duman, E., \& Öncü, S. (2016). Artırılmış gerçeklik ile motivasyon ve başarı: deneysel bir çalışma. Journal of Instructional Technologies \& Teacher Education, 5(1), 39-44.

Ibáñez, M. B., Di Serio, Á., Villarána, D., \& Kloosa, C. (2014). Experimenting with electromagnetism using augmented reality: Impact on flow student experience and educational effectiveness. Computers \& Education, 71(1-13).

İzgi Onbaşılı, Ü. (2018). Artırılmış gerçeklik uygulamalarının ilkokul öğrencilerinin artııımış gerçeklik uygulamalarına yönelik tutumlarına ve fen motivasyonlarına etkisi. Ege Journal of Education, 19(1), 320-337.

Johnson, B., \& Turner, L. A. (2003). Data collection strategies in mixed methods research. In A. Tashakkori \& C. Teddlie (Eds.), Handbook of mixed methods in social and behavioral research (pp. 297-319). Thousand Oaks, CA: Sage.

Kapil, Y., \& Roy, A. (2014). A critical evaluation of generation Z at workplaces. International Journal of Social Relevance \& Concern, 2(1), 10-14.

Karasar, N. (2012). Bilimsel araştırma yöntemi. Ankara: Nobel Yayın Dağıtım.

Korucu, A. T., Gençtürk, T., \& Sezer, C. (2016). Artırılmış gerçeklik uygulamalarının öğrenci başarı ve tutumlarına etkisi. In XVIII. Akademik Bilişim Conference, Aydın, Turkey.

Küçük, S., Yılmaz, R., Baydaş, Ö., \& Göktaş, Y. (2014). Ortaokullarda artırılmış gerçeklik uygulamaları tutum ölçeği: Geçerlik ve güvenirlik çalışması. Eğitim ve Bilim, 39(176), 383-392.

Küçük, S., Yılmaz, R., \& Göktaş, Y. (2014). İngilizce öğreniminde artırılmış gerçeklik: öğrencilerin başarı, tutum ve bilişsel yük düzeyleri. Eğitim ve Bilim, 39(176), 393-404.

Kye, B., \& Kim, Y. (2008). Investigation of the relationships between media characteristics, presence, flow, and learning effects in augmented reality based learning augmented reality. International Journal for Education Media and Technology, 2(1), 4-14.

Odabaşı, H. F. (Editör) (2010). Bilgi ve iletişim teknolojileri işığında dönüşümler. Eskişehir: Nobel Yayın Dağıtım. ISBN: 978-605-395-337-1.

Ramazanoğlu, M., \& Aker, A. (2019). Artııımış Gerçeklik Teknolojisinin Eğitim Amaçlı Kullanımına İlişkin Öğretmen Adaylarının Görüşleri. Turkish Studies-Information Technologies and Applied Sciences, 14 (1), 91-106. Erişim adresi: DOI: 10.7827/TurkishStudies.14833

Sırakaya, M., \& Alsancak Sırakaya, D. (2018). Artırımış gerçekliğin fen eğitiminde kullanımının tutum ve motivasyona etkisi. Kastamonu Eğitim Dergisi, 26 (3), 887-905. Erişim adresi: DOI: 10.24106/kefdergi.415705 
Sırakaya, S., \& Kılıç-Çakmak, E. (2016, Mayıs). Ortaokul öğrencilerinin artırımış gerçeklik uygulamalarına karşı olan tutumlarının çeşitli değişkenler açısından incelenmesi, 10. Uluslararası Bilgisayar ve Öğretim Teknolojileri Sempozyumunda sunulmuş bildiri, Rize, Türkiye Somyürek, S. (2014). Öğrenme sürecinde z kuşağının dikkatini çekme: artırılmış gerçeklik. Eğitim Teknolojisi Kuram ve Uygulama 4 (1), 63-80.

Yıldırım, S. (2016). Fen bilimleri dersinde artırımış gerçeklik uygulamalarının öğrencilerin başarısına, motivasyonuna, problem çözme becerilerine yönelik algısına ve tutumlarına etkisi. (Yayımlanmamış yüksek lisans tezi) Ankara Üniversitesi Eğitim Bilimleri Enstitüsü, Ankara.

Wang, X., Kim, M. J., Love, P. E., \& Kang, S. C. (2013). Augmented reality in built environment: classification and implications for future research. Automation in construction, 32, 1-13. 